\title{
Synchronicity of Mononuclear and Dinuclear Events in Homogeneous Catalysis. Hydroformylation of Cyclopentene using $\mathrm{Rh}_{4}(\mathrm{CO})_{12}$ and $\mathrm{HRe}(\mathrm{CO})_{5}$ as Precursors.
}

\author{
Chuanzhao $\mathrm{Li}^{1,2}$, Li Chen $^{1}$ and Marc Garland ${ }^{1,2 *}$ \\ Contribution from ${ }^{1}$ Department of Chemical and Biomolecular Engineering, \\ National University of Singapore, 117576; and ${ }^{2}$ Institute of Chemical and \\ Engineering Sciences, 1 Pesek Road, Jurong Island, Singapore, 627833 \\ * E-mail: marc garland@ices.a-star.edu.sg.
}

\section{Supporting Information}

\section{Signal Processing}

Twenty-two individual catalytic runs were carried out in batch mode with in situ FTIR measurements according to the procedure described in experimental section. The resulting 763 in situ FTIR absorbance spectra were subjected to singular value 
decomposition (SVD) ${ }^{1}$ in order to determine the associated basis vectors. Figure S1 shows a few of the first right singular vectors, as well as the $50^{\text {th }}, 120^{\text {th }}$ and $763^{\text {rd }}$. These vectors are arranged according to their contributions to signal variance. The first few vectors show distinct and localized maxima and minima and high signal to noise ratios. The $50^{\text {th }}$ vector shows a considerable increase of noise, but some localized and chemically meaningful signals are still apparent. The $120^{\text {th }}$ vector is primarily noise and the $763^{\text {rd }}$ vector is randomly distributed noise. This figure indicates that most of the chemically meaningful and useable signals are concentrated in the first circa 50 vectors.

${ }^{1}$ Golub, G. H.; Van Loan, C. F. Matrix Computations. 3rd ed.Johns Hopkins University Press, Baltimore, 1996. 


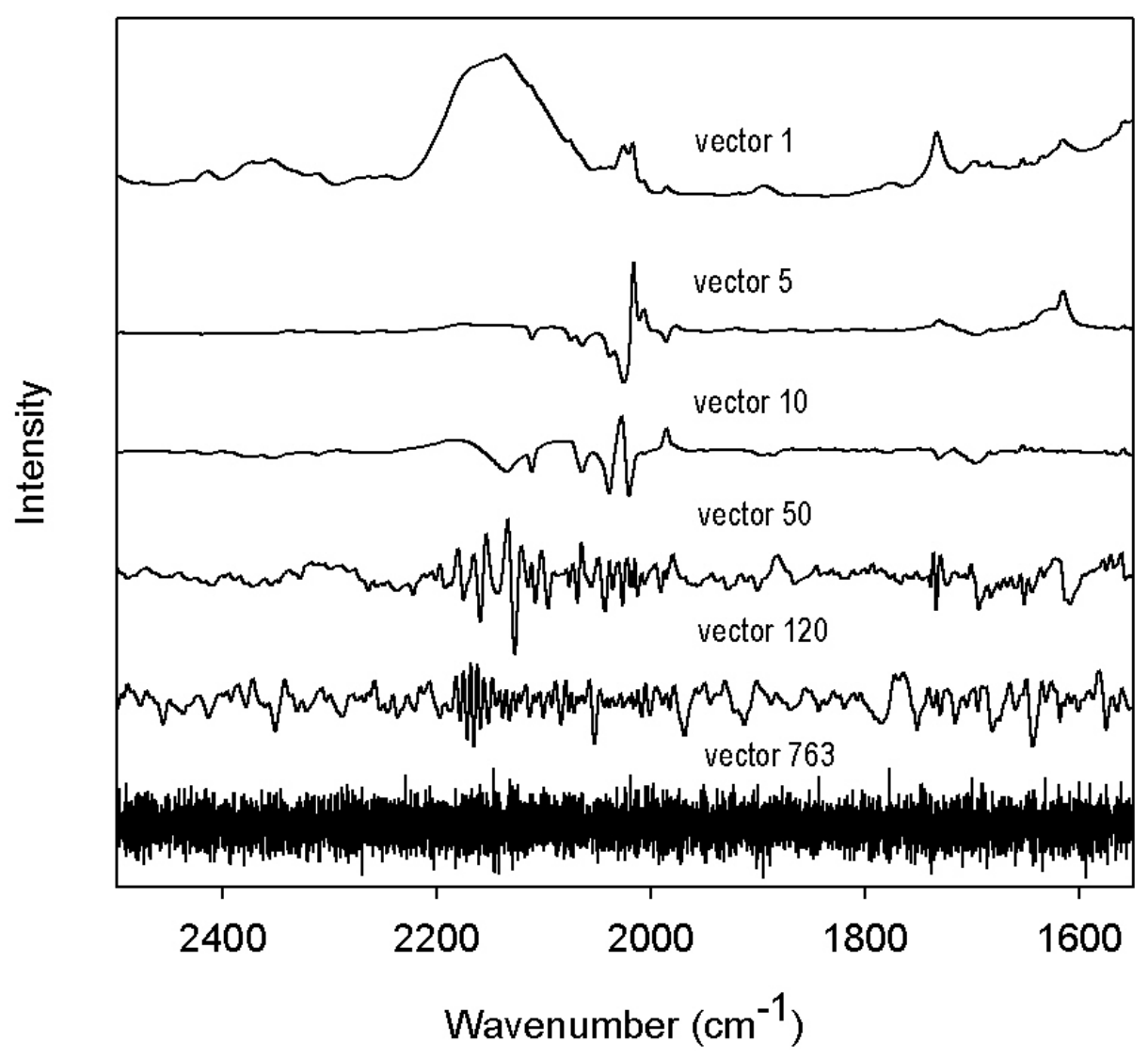

Figure S1. Singular value decomposition of the entire in situ spectroscopic data set used in this hydroformylation study. Note the high signal to noise levels in the vectors $1-10$, and the significant increase of noise by the $50^{\text {th }}$ vector.

\section{Experimental Aspects}

All hydroformylation experiments were performed in a closed batch reactor system. A recycle loop circulated the liquid phase from the reactor, through a high pressure hermetically sealed membrane pump, and a high pressure infrared spectroscopic cell (with $15 \mathrm{~mm}$ thick $\mathrm{CaF}_{2}$ windows), and then back to the reactor (recycle time circa 3 min). The reactions were all conducted in the same manner, with the same sequence of 
startup steps. All spectra were measured on a Perkin Elmer System 2000 FTIR with resolution $4 \mathrm{~cm}^{-1}$. Details of the experimental setup and a schematic diagram can be found elsewhere. ${ }^{16 \mathrm{c}}$ A stirring speed of $200 \mathrm{rpm}$ was used in all experiments. The resulted overall gas-liquid mass transfer coefficients of $\mathrm{K}_{\mathrm{La}}$ were on the order of 0.1 / s. Since the mean rate of hydroformylation was $2.3 \times 10^{-7}$ mol fraction / s, and the mean concentration of the limiting gas hydrogen was 0.01 mol fraction, the rate of mass transfer was more than 1000 time the rate of reaction, and the reactions belong to Hatta category H (infinitely slow reaction compared to mass transfer). ${ }^{2}$ The duration of a typical hydroformylation reaction was circa 5 hours and circa $15 \%$ conversion of cyclopentene was achieved in the standard experiment. Only cyclopentane carboxaldehyde could be detected as product. Mol fractions are used throughout for kinetic analyses, and all standard deviations are given with $95 \%$ confidence levels.

Table S1. The experimental design for the in-situ spectroscopic and kinetic study of the bimetallic hydroformylation of cyclopentene starting with $\mathrm{Rh}_{4}(\mathrm{CO})_{12}$ and $\mathrm{HRe}(\mathrm{CO})_{5}$ precursors.

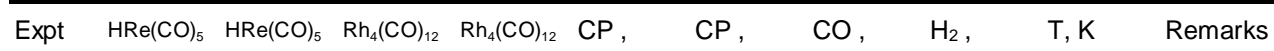

2 Garland, M. Transport Effects in Homogeneous Catalysis in Encyclopedia of Catalysis, I.T.Horvath Ed, Wiley, 2002 


\begin{tabular}{|c|c|c|c|c|c|c|c|c|c|c|}
\hline No &,$\mu \mathrm{L}$ & $\begin{array}{l}\text { Mole } \\
\times 10^{4}\end{array}$ & $\mathrm{mg}$ & $\begin{array}{l}\text { Mole } \\
\times 10^{5}\end{array}$ & $\mathrm{ml}$ & Mole & $\mathrm{MPa}$ & $\mathrm{MPa}$ & & \\
\hline 1 & 0 & 0 & 0 & 0 & 5.5 & 0.0623 & 4.0 & 1.0 & 289.7 & Blank \\
\hline 2 & 20.0 & 1.47 & 0 & 0 & 5.5 & 0.0623 & 2.0 & 2.0 & 294.3 & Pure $\mathrm{HReCO})_{5} 1$ \\
\hline 3 & 35.0 & 2.57 & 0 & 0 & 5.5 & 0.0623 & 4.0 & 1.0 & 289.7 & Pure $\mathrm{HReCO})_{5} 2$ \\
\hline 4 & 0 & 0 & 49.03 & 6.56 & 5.5 & 0.0623 & 4.0 & 1.0 & 289.7 & Pure $\mathrm{Rh}_{4}(\mathrm{CO})_{12}$ \\
\hline 5 & 20.0 & 1.47 & 42.49 & 5.68 & 5.5 & 0.0623 & 4.0 & 1.0 & 289.7 & Standard \\
\hline 6 & 5.4 & 0.40 & 39.87 & 5.33 & 5.5 & 0.0623 & 4.0 & 1.0 & 289.7 & $\begin{array}{l}\mathrm{HReCO})_{5} \\
\text { variation }\end{array}$ \\
\hline 7 & 15.0 & 1.10 & 39.37 & 5.26 & 5.5 & 0.0623 & 4.0 & 1.0 & 289.7 & \\
\hline 8 & 40.0 & 2.93 & 39.90 & 5.33 & 5.5 & 0.0623 & 4.0 & 1.0 & 289.7 & \\
\hline 9 & 20.0 & 1.47 & 9.33 & 1.25 & 5.5 & 0.0623 & 4.0 & 1.0 & 289.7 & $\mathrm{Rh}_{4}(\mathrm{CO})_{12}$ variation \\
\hline 10 & 20.0 & 1.47 & 21.38 & 2.86 & 5.5 & 0.0623 & 4.0 & 1.0 & 289.7 & \\
\hline 11 & 20.0 & 1.47 & 69.59 & 9.30 & 5.5 & 0.0623 & 4.0 & 1.0 & 289.7 & \\
\hline 12 & 20.0 & 1.47 & 37.89 & 5.07 & 3.0 & 0.0340 & 4.0 & 1.0 & 289.7 & $\begin{array}{l}\text { Cyclopentene } \\
\text { variation }\end{array}$ \\
\hline 13 & 20.0 & 1.47 & 40.40 & 5.41 & 15.0 & 0.170 & 4.0 & 1.0 & 289.7 & \\
\hline 14 & 20.0 & 1.47 & 37.17 & 4.97 & 5.5 & 0.0623 & 3.0 & 1.0 & 289.7 & $\mathrm{CO}$ variation \\
\hline 15 & 20.0 & 1.47 & 37.42 & 5.00 & 5.5 & 0.0623 & 5.0 & 1.0 & 289.7 & \\
\hline 16 & 20.0 & 1.47 & 39.42 & 5.27 & 5.5 & 0.0623 & 6.0 & 1.0 & 289.7 & \\
\hline 17 & 20.0 & 1.47 & 38.14 & 5.10 & 5.5 & 0.0623 & 4.0 & 0.5 & 289.7 & $\mathrm{H}_{2}$ Variation \\
\hline 18 & 20.0 & 1.47 & 38.67 & 5.17 & 5.5 & 0.0623 & 4.0 & 1.5 & 289.7 & \\
\hline 19 & 20.0 & 1.47 & 38.07 & 5.09 & 5.5 & 0.0623 & 4.0 & 2.0 & 289.7 & \\
\hline 20 & 20.0 & 1.47 & 40.02 & 5.35 & 5.5 & 0.0623 & 4.0 & 1.0 & 282.6 & Temperature variation \\
\hline 21 & 19.0 & 1.46 & 40.43 & 5.41 & 5.5 & 0.0623 & 4.0 & 1.0 & 294.0 & \\
\hline 22 & 18.5 & & 37.70 & & 5.5 & & 4.0 & 1.0 & 298.5 & \\
\hline
\end{tabular}

